\title{
Can't publish and be damned
}

Daniel Miller (Department of Anthropology, University College London)

A premise of academic anthropology is that we work within a structure that enables the best anthropologists producing the most scholarly and important research to make that work available to the community of anthropologists. We can therefore assume that published academic research exists to a degree commensurate with its quality. This premise is false. I believe it remains slightly more true of academic publishing in the UK than in some other countries, for example the US, but it is still false. The reason is that the forces and interests that represent the structures of publishing do not exist for the sole purpose of fulfilling this premise of academic authority. They have other interests and agendas that may not coincide with that ideal. And yet we continue to work as though there was no such discrepancy between theory and practice. This self-delusion has become increasingly problematic.

I would expect that post-graduate students continuing to work with the integrity and enthusiasm of their own research agenda are likely to be in a position of what might be called structural naivety with regard to publishing. They have been educated and brought up on the premise that publishing reflects quality and the significance of research results and they have neither the experience nor the grounds for challenging this. It is in the interest of the structure of the discipline itself to maintain that naivety since the alternative picture could be discouraging and exposes difficult questions about the inability of a discipline to realize its own ideals. I want to contest the premise with two examples, which, given in brief, will inevitably be crudely drawn. The first example is of the abuse of power in the US and the second is of the commercial imperatives within the UK.

Let me start with the worst. One would like to think academic journals and reviewing processes are 'fair'. But journals can become bastions of power, where the editors are trying to establish a particular school of thought or the authority of a particular group of people. They can use their editorial control largely as a means to those ends. With such a journal, in order to be published, one needs to send in papers replete with the 'right' citations to the 'right' people, often including those with authority over that journal. It is also possible to strive for different ideals. I recently worked as joint editor of the Journal of Material Culture and the material culture staff at UCL have agreed to curtail publishing our own work in this journal in order to try and reach an inclusive and wide interdisciplinary audience. Incidentally, there is a down side to fair editing. It means that we publish on the basis of readers' reports, not just editorial judgement. As a result, as editor I end up publishing papers I don't like and turning down papers I think are terrific-which should be born in mind before assuming our decisions necessarily reflect editorial desires. 
In contrast to what, as far as I am aware, is true of most UK anthropological publishing, I recall a talk by the editor of a US-based journal (not in anthropology) in which he made absolutely clear that the journal saw its first task as maintaining the power and authority of the journal itself. He stated that any paper submitted to the journal that did not include sufficient references to previous papers published by that same journal would not be considered for publication. Remember this was a public pronouncement, not even a private admission. This is possible because the US system is heavily biased towards giving tenure to academics who have published in a few key journals rather than publishing per se. As a result those journals with influence over tenure have considerable power to take this exclusive rather than inclusive stance.

With books the situation can be even worse. The same tenure system prioritizes certain publishers rather than others. As a result those presses that are regarded as essential for gaining tenure at the leading universities have extraordinary power to determine the career prospects for academics. After a period of time the result is almost inevitably one of abuse. I readily admit that my evidence here is based on rumours and stories, and I cannot attest to their truth. But I have heard of many cases where a press may take a manuscript, retain it for many years (years, not months) and then reject it with little by way of explanation. It is clear that this treatment is particularly common when the manuscripts have been submitted by students or junior academics, rather than senior academics. There are even rumours of sexual and other kinds of abuse associated with the power that accrues to the publisher. I assume that this would be true of only a small minority of publishers or editors, but such rumours and very possibly such practices are likely given the structural relations between tenure and the prestige of publishers. It seems most peculiar that academic reputation has been outsourced to commercial interests to this extent.

I would imagine (perhaps mistakenly) that I personally gain better treatment than many, since with twenty-three books, I start with an unusual degree of experience in book publishing and evidence of prior sales. But my own experience of US presses has often been negative. I would have expected to be consulted on the way my work is presented, the choice of front cover, a say in the blurb that is written on the back. I would have expected to be involved in promotion, to be kept informed as to how the book is going to be marketed and so forth. Finally I would have expected that the process would be carried out in reasonable time. I can think of instances of every one of these expectations proving false. There are cases where the first I have heard of the cover, blurb, and marketing event, were when I was sent the book. Even more frustrating is the extraordinary time taken by some of these presses. You submit a manuscript, hear nothing for eight months and then are asked to carry out some difficult task such as to check copy editing in ten days. Unless you pester the press you often have no idea what year the book is going to come out in, let alone the month. I have also been well treated and observed good practice, but if anything makes me appreciate working with UK publishers, it is the times when I try working with a US press.

In the UK on the whole we have managed to avoid these problems, largely I suspect because we do not have a tenure system which gives rise to this specific form of abuse. On the whole the judgement of anthropologists working within the RAE committees has been based on the individual adjudication of the publications presented in terms of their own merits, not the place in which they were published. This was a brave and these days unusual decision by those given the authority of 
adjudication and I believe has hugely beneficial effects, which one hopes will be maintained as long as possible. As long as we do not judge a book, and worse still the author, by the publisher's name on the cover there is limited opportunity for this kind of abuse.

The problem I want to highlight in UK anthropological publishing (though no doubt it applies to the US and just about everywhere else today) is of another key cause of this discrepancy between ideal and actual. This is the issue of commercial as against academic interests. My main example comes from the press I know best. I am currently producing my tenth book for Berg and have worked closely with Kathryn Earle who now owns as well as runs that press, over many years. In contrast with my experience of the US, I have found Berg to be remarkably quick in its production of manuscripts and to consult properly on all stages of production, keeping me informed and involving me in all aspects of the work, which is why I continue to enjoy working with them. But this is not at all to say that we always agree. On the contrary at least half my time is spent in dispute with Kathryn. But the disputes are 'genuine' rather than personal and acrimonious, and revolve essentially around the difference between our respective interests.

I have reached a position where I am involved with quite a number of anthropologists every year who hope I will assist as a conduit towards getting a manuscript published. This is partly because I co-edit a series for Berg with Michael Herzfeld and Paul Gilroy, which has over twenty volumes published to date, and partly because anthropology is a small world often based on trying to help each other develop our research and careers. Obviously from my point of view I would want to favour any book that I think has academic merit and would enhance the discipline as well as the individual. As an academic publisher Berg will start with a criteria of academic quality. As with a journal, a manuscript that the publisher thinks has some chance of being accepted, first goes for peer review, but if the peer reviews believe it is not academically worthy of publication it will be rejected. Most manuscripts receive a positive peer review, and sometimes there are suspicious reasons why one does not. As a discipline, we do rather better than some others in the RAE, because comparatively speaking we seem more prepared to be positive about each other rather than competitive, both as individuals and departments, and one hopes this too will remain the case in the future.

The problem is that there are far more manuscripts that can properly claim to be worth publishing on academic grounds than can be sold as commercial successes. Berg, as most presses today, including university presses, is essentially a commercial organization that survives only to the degree to which it remains profitable. As I am constantly being told by Kathryn, it is simply not in the interests of the discipline to push the company into marketing a series of unprofitable manuscripts that result in the company going bankrupt and thereby losing anthropology one of the very few British publishers that consistently publishes in our discipline. The proof of her statement is in the lack of puddings: that is, the number of independent UK presses that twenty years ago published anthropology and today either no longer exist or have been bought out by Taylor and Francis. The evidence she uses is the figures of actual sales (for example of the series I edit). Even though the sales figures for Berg tend to be higher than other publishers of academic books whose figures I have been able to gain access to, it is still clear that some books that I have recommended because I am sure that they are of considerable benefit to the discipline, have not been able to cover their costs and on reflection were a commercial mistake. Some absolutely brilliant 
scholarly and wonderful books simply have not sold. There are plenty that are successful, but the evidence is that the sales often do not correlate with scholarly quality or originality. A textbook without much of either may outsell an exemplary monograph. So the bottom line is that there are many manuscripts that on academic grounds ought to be published but are not commercially viable, and that may include your intended masterpiece.

One problem I have found working with both Berg and before them Routledge, was that topics that anthropologists tend to disdain as 'gimmicky' or where we regard the treatment as superficial, sometimes within the realm of cultural studies (though there are plenty of cultural studies works that are scholarly and of equal merit to those of anthropology) sell much better than core anthropology. This is simply because the topic in and of itself has a wider appeal across disciplines and outside of academia. There are plenty of people who want to know about Goth clothing, and clubbing, while the chances of a book on kinship or symbolic categorization gaining an audience outside of a strictly 'need to know in order to pass exam' audience is obviously limited. Though we can all point to famous examples that have transcended these limits, books that have become our anthropological classics, publishers sensibly point to the majority of books that have not achieved such status. So with the best will in the world, we have to work with publishers who have to base their policy on commercial as well as academic grounds and the conclusive evidence is that books of the highest quality do not necessarily sell.

There are still marked discrepancies between the behaviour of presses in relation to this problem. I used to edit a series for Routledge. I ended my relationship with them partly because I offered them a series of four books in the area of media anthropology including what I considered path-breaking studies of soap opera in Afghanistan and the implications of radio as soundscape which they spent years over before rejecting. No doubt they have different editors today and I do not want to cast aspersions on their current regime (actually I have been told that Routledge are no longer willing to publish in anthropology), but at the time I felt with Berg the rejections might be brutal but at least they were reasonable in terms of time taken. So there are still plenty of reasons for judging a press as more or less sympathetic and effective, irrespective of these commercial concerns. Not surprisingly there is no press at all where you will not find plenty of academics who feel they have been badly treated in some way or other.

Given this situation, what I now want to turn to is not solutions, because there are no simple solutions, but rather what we can try and do as authors to ameliorate the negative aspects of this relationship. The first thing is to recognize that a publisher who focuses upon anthropology is by definition working with very small margins and very limited time. As a first time author you might think it is entirely the publisher's job to market a book and turn it into a best seller and all you have to do is write a good scholarly book. Forget it. If you want to sell a book, and believe that it is actually quite a good thing for a book to sell more copies, then most of the work of promotion will be yours, not that of the publisher. They simply don't have the time these days to market on an individual basis anything that hasn't been carefully crafted for the purpose of sales by the author.

There are reasons why merit does not of itself necessarily sell. Until people have read your book, there is no way they can tell that despite the obscure topic and language it is actually a classic. Very, very few books are reviewed in the national press or by journals such as the TLS. Most anthropologists never receive such a review. The 
reviews they do receive, which come out in academic journals, often emerge only two or three years after publication by which time most of the sales are finished. 'Sleepers' that only start to sell after some years do exist but are very rare. So in practice reviews don't actually sell many books, which makes it difficult to know, other than by word of mouth how a book would sell by merit. Looking back I feel that of my own books, some of which I consider in retrospect to have been superior works, have in several instances sold much less well than books I now regret as more inferior works. Shockingly, but actually, books really do sell by their cover; where 'cover' stands for appearance in general, textual as well as visual. What matters is whether the topic and its treatment are presented as something individuals feel they need to spend their hard earned money on rather than get out of a library. From this consumer point of view, a book that looks like it is a textbook, that will be useful in a number of areas, or a 'classic' that will be referred to for years, or appears to be a good and enjoyable read, or relates to a topic of general and abiding interest, is going to sell more than a book that, as a monograph, can be borrowed once from a library and its contents assimilated.

But the only way the potential buyer can discriminate a book that they might want to actually buy is through the clues they pick up from things like the title, the blurb, the image and the endorsements. Or sometimes through items such as chapter headings, presentation and the first few or last few pages. In fact-simply consider what you yourself do when flicking through books last time you were in a bookshop trying to decide whether and what to buy. Then apply this to the task of selling your own book. If you are a first time author, then you are unlikely to be selling on your name. The other things an author can do is publicize their work themselves. This can be done through journal articles that makes reference to the work, through giving papers, and using the internet and other networking channels, in effect, to publicize your own work, right down to reminding teachers giving a relevant course that the book might be usefully assigned. Unfortunately English academia prides itself on a certain kind of reticence and 'cool' that distances educational capital from anything as vulgar as selling books. Yet the same individuals are mortally offended if the publisher hasn't done what they distance themselves from doing.

From the point of view of gaining a contract in the first place, an experienced publisher will quickly discern which authors have an understanding of these commercial imperatives and are going to work with them to help sell the book, and which see this as a tawdry and vulgar aspect of the publisher's own duties. And guess which one will get the contract? These days when submitting a proposal to a publisher the section on potential sales and marketing needs to be as long as the section describing the contents. Are there actual courses that you can demonstrate will use this text? Have you made the effort to show why your specific study is important to a wide range of academic issues and questions?

Anthropology has perhaps the most immediate resonance with the issues raised by commercialization of publications. At one level we have to be the most parochial of the social sciences, our work being studies of often quite particular topics based on even more particular communities. At the same time we claim to be doing this as a contribution to some grand understanding of comparative humanity. There is a case for saying that if we cannot make the link between our claims to ethnographic specificity and our claims to anthropological generality as authors, then why should either publishers or indeed readers do this for us? In general, therefore, what a publisher is looking for is a study that is taking full responsibility for outlining in full 
why it is significant to readers who are not necessarily interested in either the population studied or the specific topic. On the whole neither a monograph nor an edited collection around some parochial topic is going to find easy acceptance. It is only when the author appears to have translated their particular concern into a contribution to a larger anthropological or preferably inter-disciplinary issue that there seem grounds for arguing that the sales will cover the costs.

Negotiating with publishers is often dispiriting because they lead to a relegation of those elements of one's work the author considers significant and a re-orientation to those that will help get people to buy and read the book in the first place. We have to be consoled with the hope that if they do read the work then what we regard as significant will be encountered and make an impression. So we make compromises over titles, images and blurbs. Something I have seen time and again with first time authors is their sense of humiliation when they find that royalties are tokenistic and that they will probably spend more on the free copies of the book they need to give back to the community where we did the research than they make in those royalties. This was true for many of my own books; I made a net loss. It is humiliating since the student in question cannot help but regard the money as an evaluation of their work. But this has everything to do with our ideologies of labour and nothing to do with the actual priorities of the student in question. The chances of making significant money out of publishing academic books are not much better than winning the lottery. Once one looks at the economies of contemporary publishing and realizes that we are not being 'exploited' by some capitalist enterprise that is making vast sums at our expense, but rather that as a first time or second time author the press is probably taking a gamble on us which they may well lose, then it is probably worth trying to disengage from this sense of money as evaluation. My first book contract was with Cambridge University Press, and was for 0\% royalties. I do not regret it.

There is, however, a still deeper problem. Even if authors do everything right about trying to make their work commercially acceptable. Even if publishers working in academia try to accept some lower selling works and hope to balance this with more successful books. We have reached a point in the history of anthropology where there are manuscripts being produced that are undoubtedly worth publishing from an academic perspective, but will never gain the sales that make them acceptable to a commercial press. What is going to happen to those manuscripts? It was with this question in mind that I recently approached Sean Kingston, an ex-student of my department at University College London. For some time I had wondered about the development of 'print on demand' as a technology. I was starting to find some of my own books that I had thought out of print suddenly re-appearing in bookshops (without the publishers in question ever bothering to inform me that this was happening!) Sean Kingston had been developing a press that took print on demand as its foundation rather than simply an extra element of re-publishing. He already had contracts with several authors including Marilyn Strathern. In this case, the publisher is able to make a profit on a smaller number of books, because less money is spent on marketing, publicity and distribution. It uses state of the art printing which allows one to print in much smaller numbers, which in turn means that one prints essentially to a known quantity of sales so there is no danger of large surpluses that have to be stored or sold at a loss. It is possible to imagine online publishing with books following journals, though there are other problems with that solution, such as trying to download and print a whole book. 
From my point of view the development of a new series had to take into account the wider context of an individual's reputation and career. My primary concern was with post-graduate students and first time authors. They were the most vulnerable to the vicissitudes of current publishing. It was my students who had suffered from the experience of having a press take their work for years and then reject it or find themselves unable to find a press despite countless attempts, even when I assured them again and again that the work was academically significant and worth publishing. The problem was that if a print on demand series was simply viewed as the publisher of last resort and had less academic reputation than say Berg or Cambridge University Press then it would fail to address the key issue, which was that a failure to be commercially viable need not mean that the actual scholarship or quality of the work was less than a commercially viable book. In short the biggest problem was the original premise that publishing automatically reflects quality. So in setting up the press we started by an approach to 'the great and the good' such as Mary Douglas, Marilyn Strathern and Maurice Bloch and asked them if they would constitute the board of this series. Our argument was that if such anthropologists would give their imprimatur to the series and if they would themselves act as readers of the manuscripts in question and agree that the books merited being published, then one could make an incontestable argument that the only reason these manuscripts were not going to another press was commercial rather than academic. Fortunately almost all those approached agreed to take on this role and so it was possible to create such a series.

We picked a title, Anthropology Matters, at a time when I have to confess I had never seen the publication I am writing this paper for. My own feeling is that this coincidence has a benign side to it in as much as the people we were trying to construct our series on behalf of are precisely the same group that this journal was designed for, the contemporary post-graduates and junior staff within British anthropology. We have now added 'scholarship on demand' to our title to avoid any confusion. But I am writing this largely because I would like to see the two ventures as essentially complementary attempts to forward the interests of the very same community. If this journal provides a conduit to early and initial publication of articles then our series may provide a conduit to early and initial publication of books. If it manages to rescue your own worthy work from undeserved oblivion then that is its purpose. The series has now been established and the first book Of Alien Kings and Perpetual Kin by Manuela Palmeirim is due out in February 2006 (see http://www.seankingston.co.uk/publishing.html).

At one level I would be perfectly happy if our series failed, as long as that meant it wasn't actually needed. I confess I have absolutely no desire for the work involved in setting up a series and I do not suppose any of the editorial board are looking for extra work either. But anthropology is hopefully a rather more socially responsible discipline than most, and my sense of British anthropology is that there remains a sense of the collective good and the collective interest rather than any descent into invidious competition. It is the spirit that I imagine engendered this journal. What is tragic is to see excellent academic work that simply cannot reach an audience.

I am writing this paper primarily to confront the premise with which I started. In an ideal world a book would find ease of publication and reward by royalties directly commensurate with its quality. But there are problematic consequences in believing that we live in this ideal world. It means that when we find that our own book is hard to publish and is given only token royalties we take it as a personal slight on the 
quality of our work. This is both false and unfortunate. It seems to me that it would be better to start with the reality that anthropology books are almost entirely published by publishers who have to survive commercially and learn how we can work with these publishers to promote and sell books or to find alternative publishing outlets that can afford to publish our books, so that we can at least say that we have done what we can to ensure that scholarship reaches the audience it deserves. I also hope that the British anthropological community will continue to evaluate academic work individually on merit rather than on the basis of who has published it.

\section{About the author}

Daniel Miller is Professor of Material Culture at the Department of Anthropology, University College London. His most recent books are Ed, Materiality (Duke University Press 2005) and Ed with S. Küchler. Clothing as Material Culture (Berg 2005). He is currently working on three collaborative projects: mobile phones and poverty in Jamaica, Slovak au pairs in London, and memory and loss in South London. 